\title{
Study on the impact of sudden stratosphere warming in the upper mesosphere-lower thermosphere regions using satellite and HF radar measurements
}

\author{
N. Mbatha ${ }^{1,2}$, V. Sivakumar ${ }^{3,4,5}$, S. B. Malinga ${ }^{2}$, H. Bencherif ${ }^{5}$, and S. R. Pillay ${ }^{1}$ \\ ${ }^{1}$ School of Physics, University of KwaZulu-Natal, Durban 4000, South Africa \\ ${ }^{2}$ Hermanus Magnetic Observatory, P.O. Box 32, Hermanus 7200, South Africa \\ ${ }^{3}$ National Laser Centre, Council for Scientific and Industrial Research, P.O. Box 395, Pretoria 0001, South Africa \\ ${ }^{4}$ Department of Geography, Geoinformatics and Meteorology, University of Pretoria, Lynwood Road, \\ Pretoria 0002, South Africa \\ ${ }^{5}$ Laboratoire de l'Atmosphère et des Cyclones, UMR 8105 CNRS, Université de La Réunion, 97715 Saint-Denis, Cedex 9, \\ La Réunion, France
}

Received: 3 July 2009 - Published in Atmos. Chem. Phys. Discuss.: 2 November 2009

Revised: 18 February 2010 - Accepted: 29 March 2010 - Published: 12 April 2010

\begin{abstract}
The occurrence of a sudden stratospheric warming (SSW) excites disturbances in the mesosphere-lower thermospheric (MLT) wind and temperature. Here, we have examined the high frequency (HF) radar wind data from the South African National Antarctic Expedition, SANAE $\left(72^{\circ} \mathrm{S}, 3^{\circ} \mathrm{W}\right)$, a radar which is part of the Super Dual Auroral Radar Network (SuperDARN). Sounding of the Atmosphere using Broadband Emission Radiometry (SABER) on board the Thermosphere-Ionosphere-Mesosphere-Energetics and Dynamics (TIMED) satellite temperature data and National Centre for Environmental Prediction (NCEP) temperature and wind data are used to investigate the dynamical effects of the unprecedented September 2002 SSW in the Antarctica stratosphere and MLT. The mean zonal wind (from SANAE HF radar) at the MLT shows reversal approximately 7 days before the reversal at $10 \mathrm{hPa}$ (from NCEP). This indicates that there was a downwards propagation of circulation disturbance. Westerly zonal winds dominate the winter MLT, but during the 2002 winter there are many periods of westward winds observed compared to other years. The normalised power spectrums of both meridional and zonal winds show presence of planetary waves (of $\sim 14$-day period) before the occurrence of the SSW. The SABER vertical temperature profiles indicated the cooling of the MLT region before the SSW event.
\end{abstract}

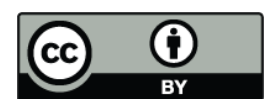

Correspondence to: N. Mbatha (nmbatha@hmo.ac.za)

\section{Introduction}

The first ever detection of a major SSW in the Southern Hemisphere (SH) occurred during 2002 Antarctic winter (Baldwin et al., 2003). During this exceptional event the $60^{\circ} \mathrm{S}$ winds at $10 \mathrm{hPa}$ reversed on the 26th of September, before it returned to a weak flow on about 15 th October. The primary cause of the sudden stratospheric warming (SSW) is thought to be planetary waves originating from the troposphere and propagating upwards to the stratosphere and mesosphere lower-thermosphere (MLT) region (Matsuno, 1971; Holton, 1976; Andrews et al., 1987). These planetary waves interact with the mean-flow and due to that interaction an upward and pole-ward directed heat and momentum flux leads to decreasing eastward winds and increasing temperature in the polar region (Matsuno, 1971; Hoffmann et al., 2002).

Planetary scale waves are generated in the troposphere by topographic and thermal features, and propagate up into the middle atmosphere (Shepherd, 2000). The instabilities arising from horizontal and/or vertical gradients in the temperature and wind disturbances can also induce planetary waves. Because of the topography of the Northern Hemisphere $(\mathrm{NH})$, planetary wave energy is significantly large in the $\mathrm{NH}$ compared to the $\mathrm{SH}$, and hence the usual detection of the SSW in the NH. Planetary and gravity waves are critical for mixing processes and for the Brewer-Dobson circulation in the middle atmosphere. The winter hemisphere is dominated by large amplitude stationary planetary waves which

Published by Copernicus Publications on behalf of the European Geosciences Union. 
originate from the troposphere. Intermittently these waves break, stirring air more or less isentropically across large distances of the stratosphere within a region that has become known as the "surf zone", bounded by sharp gradient of potential vorticity (PV) and of tracers in the winter subtropics and the edge of the polar vortex (Plumb, 2002; Sivakumar et al., 2004). In fact, interactions between planetary waves and the zonal-mean flow in the middle atmosphere induce a westward forcing in the winter hemisphere, resulting in deceleration and/or reversal of the eastward winter polar night jet. The deceleration and reversal of the eastward polar night jet in the high-latitude stratosphere also changes the filtering of internal gravity waves and allows increasing amounts of eastward propagating gravity waves from the troposphere to penetrate into the MLT and break there, while blocking westward propagating gravity waves (Sathishkumar and Sridharan, 2009). Hence, the eastward forcing due to eastward propagating gravity wave breaking increases and may even replace the previously dominant westward forcing in the MLT. This process also changes the meridional circulation in the upper mesosphere from pole-ward/downward to equator-ward/upward (Liu and Roble, 2002).

Labitzke and Naujokat (2000) classified a SSW as a minor warming if there is a significant increase of temperature (at least by $25 \mathrm{~K}$ per week) below $10 \mathrm{hPa}$ levels in any area of the winter hemisphere. This temperature increase can be intense and sometimes also reverse the temperature gradient, but they may not lead to wind reversal at/below the $10 \mathrm{hPa}$ pressure level. On the other hand, a SSW is classified as a major warming if at $10 \mathrm{hPa}$ height or below the latitudinal mean temperature increases pole-ward from $60^{\circ}$ latitude and an associated wind circulation reversal leads to a change from the usual dominant eastward directed flow to westward directed flow and hence to a splitting of the polar vertex. In late September 2002, the first ever major SSW observed in the $\mathrm{SH}$ occurred in the polar region.

In the winter hemisphere, the stratospheric and MLT temperature and wind at high- and mid-latitudes can undergo significant changes before, during, and after the occurrence of a SSW (e.g., Walterscheid et al., 2000; Cho and Shepherd, 2004; Liu and Roble, 2005). These changes can range from the zonal mean wind reversal (Dowdy et al., 2004) to the cooling of the MLT temperature (Hernandez, 2003; Liu and Roble, 2005). Dowdy et al. (2004) used three medium frequency (MF) radars located at Davis $\left(69^{\circ} \mathrm{S}, 78^{\circ} \mathrm{W}\right)$, Syowa $\left(69^{\circ} \mathrm{S}, 40^{\circ} \mathrm{W}\right)$ and Rothera $\left(68^{\circ} \mathrm{S}, 68^{\circ} \mathrm{W}\right)$ to study the dynamics of the MLT during the SH 2002 SSW. In their study, the most noticeable feature was the reversal of the mesospheric zonal winds a week earlier before the reversal in the stratosphere, and a different winter mesospheric wind field in 2002 compared to the other years, primarily due to the increase of planetary wave activity during winter. This behaviour shows similarities when compared to studies of the major SSWs in the NH. According to Baldwin and Dunkerton (1999), Polar stratosphere-to-troposphere cou- pling events are often preceded by a disturbance in the upper atmosphere. Observations by Hoffmann et al. (2002) and Hoffmann (2007) showed that mesospheric cooling and MLT zonal wind reversals occur prior to the SSWs.

Although there are number of MF radars in Antarctica, any available wind measurements, especially from a global network of identical instruments like Super Dual Auroral Radar Network (SuperDARN) is a desirable option for studying wind variations dynamics, atmospheric waves, and associated characteristics in the MLT region. While Dowdy et al. (2004) used MF radars with operation frequencies between 1.94 and $2.40 \mathrm{MHz}$ in their study, we have used only one SuperDARN high frequence (HF) radar with operating frequencies between 8 and $20 \mathrm{MHz}$, situated in SANAE base $\left(72^{\circ} \mathrm{S}, 3^{\circ} \mathrm{W}\right)$, Antarctica. Origionaly, SuperDARN radars were designed to study plasma flow in the high-latitude ionosphere. However, Hall et al. (1997) demostrated that echoes at ranges close to the SuperDARN radars are actually due to scatter from meteor trails near $94 \mathrm{~km}$ altitude. Therefore, the near-range scatter can be utilised to study neutral winds at meteor heights. Thus, The procedure used to retrieve wind data from SuperDARN is different from the MF radars, and to study the unpreceded 2002 September SSW influence in the MLT using SANAE SuperDARN radar also contributes to the understanding of the dynamics of the MLT in September 2002. In recent years, we have seen an increase in number of studies which utilize the HF radar wind data to study the MLT dynamics (e.g. Bristow et al. (1999); Hussey et al. (2000); Espy and Hibbins (2005); Malinga and Ruohoniemi (2007) etc.). Due to the unusual behaviour of the Antarctica stratosphere in 2002, it is expected that the MLT wind field measured by SANAE HF radar also exhibits similar behaviour. Espy and Hibbins (2005) proved capabilities of SuperDARN HF radars to study SSW events by examining meridional winds from Syawo, SANAE and Halley stations and also the Rothera MF radar in order to assess whether long quasi-periodic oscillations in 2002 has a longitudinal phase progression characteristic of planetary waves. Our results compliments Dowdy et al. (2004) where the similar behavior of the middle atmosphere is experienced when using different type of radar. Our present results are measured exclusively from HF radars and is interesting for the first time (based on SANAE) to explore the SSW influences in the MLT region. We extend our work by inverstigating the wave activity before, during, and after the SSW, using Fourier analyses technique. We examine zonal and meridional wind data from SANAE HF radar to explore the response of the MLT to the SSW. The details of the HF radar are explained in the following section. NCEP reanalysis temperature and zonal wind data are used to identify the SSW as well as to examine variations of temperature and zonal wind in the stratosphere during the SSW event. The Sounding of the Atmosphere using Broadband Emission Radiometry (SABER) on board the Thermosphere-IonosphereMesosphere-Energetics and Dynamics (TIMED) satellite is 
used to examine temperature structure in the middle atmosphere during the 2002 SSW event.

\section{Instruments and method}

\subsection{SANAE HF radar and data acquisition}

The SANAE HF radar is part of the SuperDARN Radar network and it is located in Antarctica $\left(72^{\circ} \mathrm{S}, 3^{\circ} \mathrm{W}\right)$. SuperDARN (Greenwald et al., 1995) is a network of HF radars originally designed to study plasma flow in the high-latitude ionosphere. Hall et al. (1997) confirmed that echoes at ranges close to the SuperDARN radars are actually due to scatter from meteor trails near $94 \mathrm{~km}$ altitude, except during periods of high $K_{p}$ (an indication of geomagnetic disturbance). Hence, the near-range scatter can be utilised to study neutral winds at meteor heights. Greenwald et al. (1995) have reviewed the SuperDARN radars and their operation, thus, in the present work only a brief description of the SuperDARN radars is given.

The SuperDARN radars operate at frequencies between 8 and $20 \mathrm{MHz}$. Each radar site consist of 16-antenna array connected to a phasing matrix which permits the single beam to be swept through 16 successive positions in increments of $3.25^{\circ}$, giving an azimuth extent of $\sim 52^{\circ}$. The azimuthal resolution depends on the operating frequency and it ranges from $2.5^{\circ}$ at $20 \mathrm{MHz}$ to $6^{\circ}$ at $8 \mathrm{MHz}$. The peak power is about $10 \mathrm{~kW}$ and the range resolution is $30-45 \mathrm{~km}$ with a typical pulse width of 200-300 $\mu$ s. Measurements are taken for every $7 \mathrm{~s}$ at each of the 16 beam positions. The backscatter information from these pulses is sampled and then processed giving multi-lag autocorrelation functions (ACFs). The ACFs are thereafter used to deduce backscatter power, mean Doppler velocity and the width for the Doppler power spectrum for each range with significant returns and the pulse sequence is about $40 \mathrm{~ms}$ duration, and pulses sequence is separated by $60 \mathrm{~ms}$, giving $60 \mathrm{ACFs}$ in each of the 7 transmitting seconds; and these are averaged together for each measurement.

The SuperDARN radars were primarily designed to study the convection patterns in the high-latitude ionosphere. However, there are several studies which have proved that $\mathrm{Su}-$ perDARN radars can also be used to study the dynamics of the MLT region. For example, Hussey et al. (2000) performed a comparison of $\mathrm{NH}$ winds using SuperDARN meteor trail and Saskatoon $\left(52.2^{\circ} \mathrm{N}, 106.6^{\circ} \mathrm{W}\right) \mathrm{MF}$ radar wind measurements. In their results, they found good agreement between the two radar systems at altitude of $\sim 95 \mathrm{~km}$. Bristow et al. (1999) also compared SuperDARN wind results with those of High Resolution Doppler Imager (HRDI) aboard the Upper Atmosphere Research Satellite (UARS) and found that both instruments observed a 2-day wave with wave number-3. Malinga and Ruohoniemi (2007) used the
SuperDARN radar network in the NH to study the characteristics of the quasi-two-day wave at meteor heights.

The meteor trail echoes occur predominantly in and below the lower $E$ region $(\sim 95 \mathrm{~km})$ (Hussey et al., 2000), thus acquisition of the winds in the meteor region is accomplished by using data from the first several range gates of the radar. The backscatter at this distance is primarily due to meteors and thus a nominal height of $90-95 \mathrm{~km}$ is assumed. Hourly wind averages are computed for each beam direction giving a line of-sight wind velocity. Figure 2 depicts the hourly averaged zonal winds observed by SANAE HF radar during September 2002. The mean winds were deduced by averaging 4-day time sequence of hourly averaged zonal and meridional wind velocities (see Fig. 3). The 4-day data window is then shifted by 1-day at a time and the average of the data window are attributed to the second day of the interval.

\subsection{TIMED/SABER temperature data and NCEP data}

In the present study, the vertical temperature profiles are derived from the version 1.07 of SABER level 2A data (downloaded from the web site http:/saber.gats-inc.com). The TIMED satellite was launched on 7 December 2001 into a $625 \mathrm{~km}$ orbit of $74.1^{\circ}$ inclination, and the SABER instrument began taking measurements in late January 2002. By step-scanning the atmosphere limb, SABER measures height profiles of temperature and selected chemical species in the $10-180 \mathrm{~km}$ altitude range, with a horizontal resolution along track of $400 \mathrm{~km}$. Details about the SABER temperature data and SABER sampling are given by Remsberg et al. (2003).

Temperature and wind fields used to follow the evolution of the SSW event are obtained from the NCEP/NCAR reanalysis project available on the web at (http:/www.cdc. noaa.gov/). This co-operational project between NCEP an NCAR provides daily meteorological values on $2.5^{\circ}$ latitude by $2.5^{\circ}$ longitude resolution. The NCEP/NCAR reanalysis data is formed by the combination of the assimilation of data from different meteorological instruments which are scattered globally. In the present study, we have used the NCEP zonal-mean zonal winds at $60^{\circ} \mathrm{S}$ and $10 \mathrm{hPa}$ pressure levels $\left(\sim 32 \mathrm{~km}\right.$ height) and zonal-mean temperature at $80^{\circ} \mathrm{S}$ and $10 \mathrm{hPa}$ to examine wind and temperature daily variation during 2002 winter period (see Fig. 1).

\section{Mean wind results and planetary waves signature during the SSW}

Figure 3 shows the daily averaged zonal and meridional wind derived from the SANAE HF radar observations from the start of July until the end of November 2002 (black dashed line), superimposed on the average wind and its standard deviation values based on the same observations from 2003 to 2006 (gray line). The years from 2003 to 2006 were identified as the period where there is no SSW observed. 


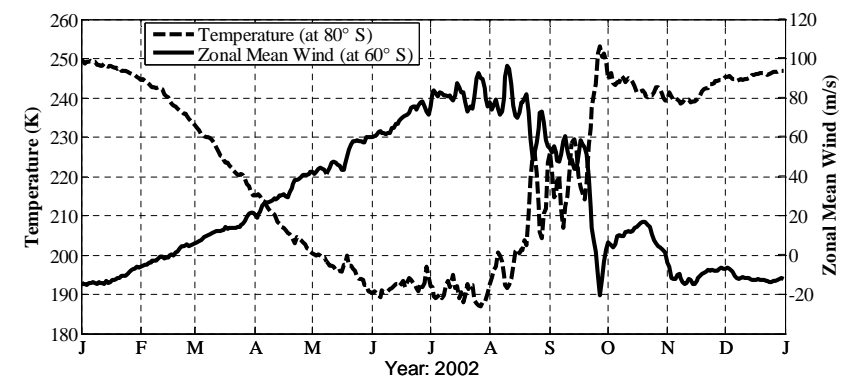

Fig. 1. 2002 records of daily zonal mean wind at $60^{\circ} \mathrm{S}$ (solid line) and temperature at $80^{\circ} \mathrm{S}$ (dotted line) from NCEP reanalysis.

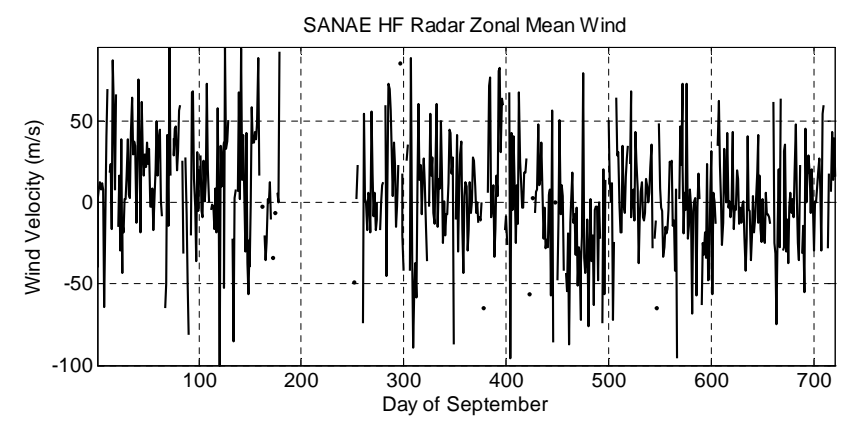

Fig. 2. Hourly averaged zonal mean wind as observed by the SANAE HF radar during September 2002.

Thereby, the 2003-2006 averages represent the background wind patterns. During the period July-November one can see from Fig. 3a that eastward winds are primarily dominant in the polar winter in the MLT particularly during August and September. The reversals of zonal mean wind start at around the beginning of July, which is approximately two months before the occurrence of the SSW in late September. The reversal of the zonal wind which is associated with the SSW event is well outside the standard deviation of the 2003 to 2006 average and starts on 18 September (day 261, from Fig. 3a) and persisted for a few days before it returned to eastwards direction on 27 September (day 270) while in the stratosphere the zonal wind reversed on 25 September 2002 (Fig. 1) leading to the unprecedented major SSW in the Southern Hemisphere. This is consistent with results from Dowdy et al. (2004). They reported from MF radars at polar locations that during the 2002-major warming zonal wind in the mesosphere became westwards on day 261 (18 September), approximately a week earlier than the $10 \mathrm{hPa}$ winds turned westwards. The meridional mean winds during 2002 also show an enhancement during the period of the occurrence of the SSW event and this feature is not seen in the other years (see Fig. 3b). Maximum reversals of meridional mean winds are seen on day 242 and 270.

Figure 4 shows the time evolution of the zonal wind at $10 \mathrm{hPa}(\sim 32 \mathrm{~km})$ derived from the NCEP at $60^{\circ} \mathrm{S}$ latitude during the period from 250 to 300 Julian days in 2002. The
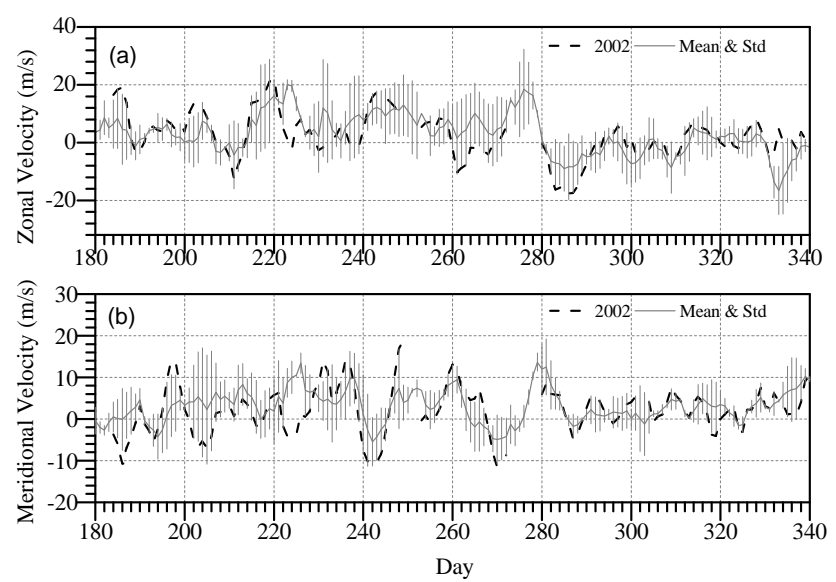

Fig. 3. Time evolution of daily averaged (a) zonal and (b) meridional velocities obtained from SANAE HF radar observations from 1 July to late November 2002. The figure is superimposed with the 2003-2006 mean profile with standard deviation.

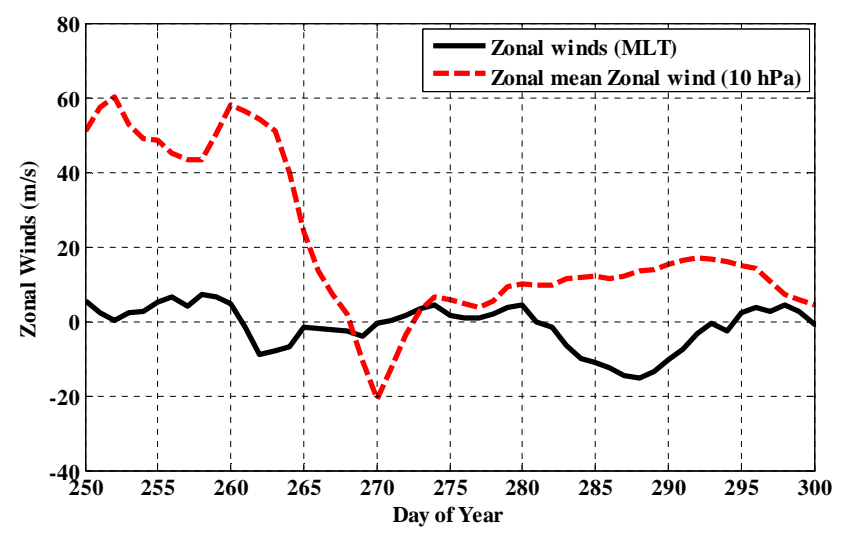

Fig. 4. Zonal wind evolution in the MLT region ( $~ 94 \mathrm{~km})$ obtained by SANAE HF radar (solid black line) during the period from 250 to 300 (of year between) 2002-Julian days. The red dashed line illustrates the zonal-mean zonal wind variation at $10 \mathrm{hPa}(32 \mathrm{~km})$ derived from NCEP reanalyses at $60^{\circ} \mathrm{S}$ for the same period of time.

zonal wind observations from SANAE HF radar (for $\sim 94 \mathrm{~km}$ MLT height) are superimposed with a solid black line. The SANAE HF radar data is smoothened by a 4-day running mean. The figure shows that the zonal wind started to reverse (became westward) in the MLT region on the 261th 2002-Julian day (18 September), i.e., about a week earlier than the reversal of the zonal wind in the polar stratosphere at $\sim 10 \mathrm{hPa}$ pressure level. The reversal in the MLT reaches a maximum magnitude of about $-10 \mathrm{~m} / \mathrm{s}$ on the 263th day (20 September 2002). The MLT zonal winds reversal lasted for a few days and thereafter returned to the eastward direction for more than 10 days, before another reversal which starts on day 282 (9 October) and persists until the beginning of summer. The reversal in the stratosphere begins on the 268th day and reaches its maximum amplitude of $-20 \mathrm{~m} / \mathrm{s}$ on day 270 

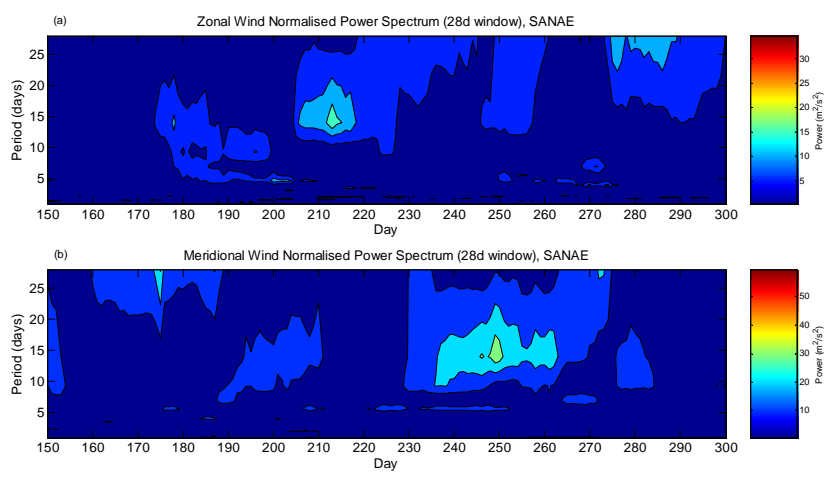

Fig. 5. Normalised Power spectra of daily zonal (a) and meridional wind (b) derived for the MLT region $(\sim 94 \mathrm{~km})$ from SANAE HF radar for the period from 30 May to 27 October 2002 (150-300 Julian days).

before it turns back to the eastward direction on day 273. It is noted here that the daily variability of the zonal wind may vary from day to day and time to time, but it is found to be within $\pm 8 \mathrm{~m} / \mathrm{s}$.

As discussed in Matsuno, (1971), Andrews et al. (1987), Dowdy et al. (2004), etc., the dynamical mechanisms behind SSW generation involves planetary and gravity wave propagation from the troposphere into the middle atmosphere where they interact with mean flow. In order to examine wave characteristics in the MLT region from the SANAE HF radar data, it is necessary to determine the dominant spectral components within the frequency band of interest. Thus, to do this, we performed dynamic Fourier spectra using a 28-day data window that is shifted forward by 1-day at a time. The deduced power for a given data window was attributed to a central day given by day 14 of that particular 28-day data interval. This long data window results in the desired frequency resolution of 0.0357 cycles per day (cpd). However, the problem with this frequency resolution is at the expense of time resolution. This is mainly important because planetary waves with short periods e.g. quasi-two-day waves which is characterised by bursts of activity that varies on scales of several days (Pancheva, 2006; Malinga and Ruohoniemi, 2007). Nevertheless, for the purpose of deducing the signature of planetary waves, the 28-day data window is a suitable compromise and has been used where proper in the present study.

The contour plots in Fig. 5 shows the dynamic spectra analysis applied to the zonal and meridional wind components of SANAE HF radar wind data. Here, we have only plotted the normalised power for the period from May to late October (150 to 300 Julian days). The sampled height is $\sim 94 \mathrm{~km}$. The power has been normalised by $\sigma^{2} / N$, where $N$ is the number of data points and $\sigma^{2}$ is the variance of the time series. Using this normalization, white noise would have an expectation value of one at all frequencies (Torrence and Compo, 1998). From Fig. 5a it can be clearly seen that
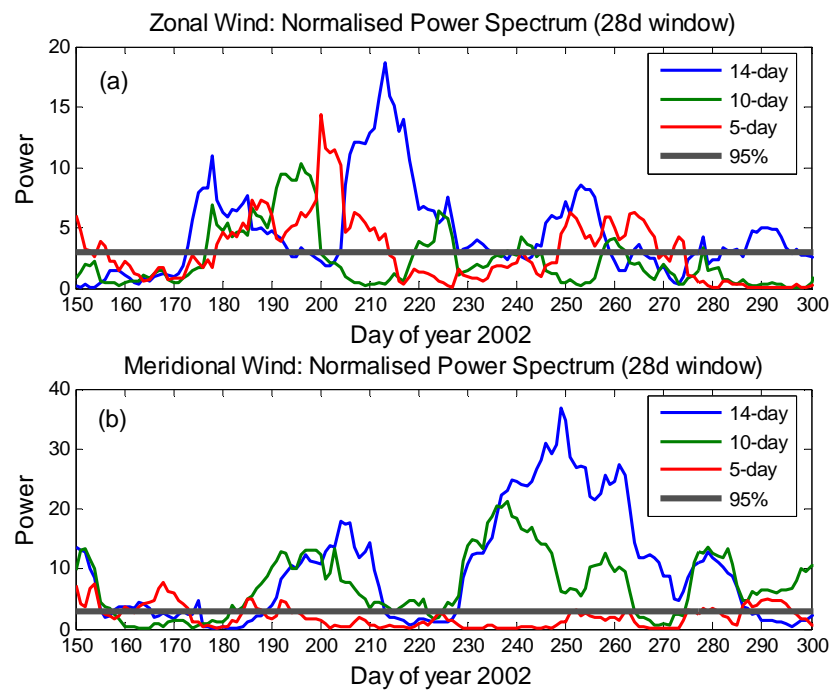

Fig. 6. Normalised power spectrum of the zonal wind (a) and meridional wind (b) 14-, 10-, and 5-day components for SANAE HF radar. The gray horizontal line represents the $95 \%$ confidence level.

the zonal wind power spectra is characterised by dominant peaks near to periods of 5-day, 10-day and 14- to 16-day waves in the mid-winter. The 5-day and 14- to 16-day waves are also seen around 250th of 2002 Julian day (7 September), and this period is about 2 weeks prior to the occurrence of the SSW. When comparing the year 2002 spectra to the other years (the figures are not shown) we see that other years do not have strong presence of the above mentioned planetary waves. The spectrum for the meridional wind component which is shown in Fig. $5 \mathrm{~b}$ also shows the presence of a 14to 16-day wave around 7 September (250th of Julian days). There is also an evidence of a 5-day wave on the spectrum. In Fig. 6 we have plotted the normalised Fourier power spectra of the 14-, 10-, and 5-day waves for (a) zonal and (b) meridional components, respectively. The horizontal gray thick line indicates the $95 \%$ confidence level using a chi-square test, assuming white noise as background spectrum (Torrence and Compo, 1998). From the figure, it is clear that zonal 14, 10- and 5-day waves have a seasonal pattern characterised enhance wave activity in winter superimposed by short-term fluctuations. The winter wave activity tends to be above the $95 \%$ confidence level. We observe a burst of wave activity from around day 173 to 229 . The zonal 14-day wave activity has the strongest peak in day 213 . The meridional component has the strong presence of wave activity with an exception of the 5-day wave which is always under the $95 \%$ confidence level. The meridional 14-day wave activity reaches its peak on day 250. 


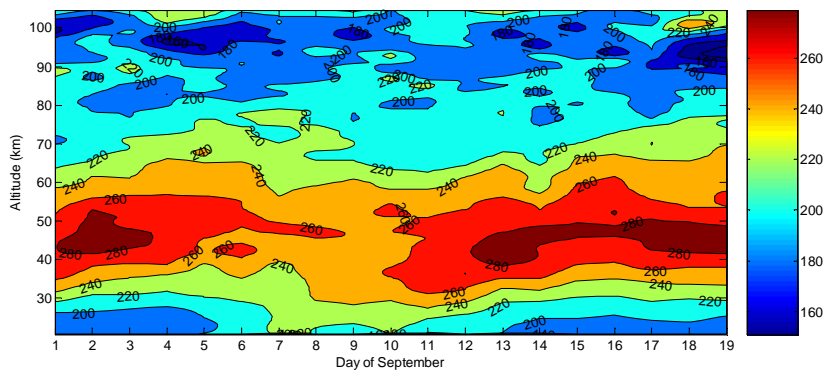

Fig. 7. Altitude - Temperature contour map obtained from the SABER data for successive days from 1 to 19 September 2002 (244-262 Julian days). The data corresponds to the satellite closest overpass above SANAE site.

\section{Link with temperature variations}

Previous studies have associated the occurrence of SSW events with the cooling of the MLT temperature (e.g. Walterscheid et al., 2000; Hernandez, 2003; Liu and Roble, 2005). Hernandez (2003) reported a cooling of the mesopause region over the South Pole during the 2002 SH stratospheric sudden warming. Liu and Roble (2005) used a Global Circulation Model (GCM) extending from 30 to $500 \mathrm{~km}$ to examine the interaction between planetary wave forcing and the evolving zonal mean state during the same event. They found significant mesospheric effects which include a cooling and reversal of the zonal wind prior to the SSW event. Figure 7 shows temperature contour maps obtained from SABER satellite data plotted for successive days from 1 to 19 September 2002 (244-262 Julian days). The main idea was to use those SABER temperature data which are closer to the SANAE base during September 2002. However, SABER obtains profiles from $52^{\circ} \mathrm{S}$ to $83^{\circ} \mathrm{N}$ during its north-looking mode for 60 days before switching to an analogous southlooking mode and then repeats that sequence for the subsequent months (Remsberg, 2003). In this way, the polar cap data is available only in 60-day segments, with no information for the 60 days preceding or following. Thus, only the first 19 days of September 2002 are closer to the SANAE base $\left(72^{\circ} \mathrm{S}, 3^{\circ} \mathrm{W}\right)$. The 19 profiles used in this work are the closest as the satellite overpasses over the SANAE site.

Figure 7 shows the structure of the altitude variation of vertical temperature prior to the occurrence of the major SSW which only reaches its maximum on the 26th of September 2002. In fact, such warming drive an unusual dynamical situation resulting in the split of the polar vortex (Baldwin et al., 2003) and transport of air-masses from pole to mid- and low-latitudes (Bencherif et al., 2007). The most noticeable feature in these temperature profiles is a substantial increase of temperature (at the rate of $5 \mathrm{~K} /$ day) throughout the stratosphere which is visible on the 13th to the 19th of September. Baldwin et al. (2003) illustrated the daily variation of temperature for the stratosphere at the South Pole using NCEP/NCAR reanalysis from 1979 to 2002 (in their
Fig. 3). The polar temperature in late September 2002 was extremely high, indicating this is an unprecedented event at least in the past 24 years. Thus, the increase of temperature which reaches a maximum of $240 \mathrm{~K}$ at around $32 \mathrm{~km}$ and $280 \mathrm{~K}$ at around $40 \mathrm{~km}$ is uncommon and is associated with a SSW. Moreover, it can be mentioned that before this major warming event, which reached its peak on 26 September, a few minor warming's can be seen during the 2002 winter period primarily in mid-July, mid- and late-August onwards, until the beginning of September (see Fig. 1). At mesospheric heights, the vertical temperature profiles illustrate the persistence and the variability of the mesospheric temperature inversion layer during the continuous series of SABER measurements. These inversion layers are primarily observed between 70 and $110 \mathrm{~km}$ and in all profiles with a stronger signature on the 17th, 18th and 19th of September. Thus, there are signatures of mixing and viscous dissipation associated with turbulence generated by the breaking upward propagating gravity waves in the MLT region. Although according to Meriwether and Gerrard (2004) the mesospheric inversion layers can appear in the MLT region of the lowlatitude and midlatitude at any time of the year, the mesospheric inversion layers seen in our results over SANAE are an interesting future which still needs to be investigated in details.

\section{Discussion and conclusions}

In the present study, the HF radar data set from SANAE base in Antarctica is used to examine the dynamical structure of the MLT region during the unprecedented major SSW occurred in late September 2002. Only MF radars are usually used for this purpose both in the southern and Northern Hemispheres. This work highlights and strengthens the idea that HF radars enable us to investigate dynamical processes on the MLT region. In our results, we have shown that the mean zonal wind (from SANAE HF radar) throughout 2002 winter at $\sim 94 \mathrm{~km}$, display an enhancement due to a series of large planetary wave amplifications in the stratosphere during this period. The large amplitude planetary wave produces strong westward forcing in the high-latitude winter stratosphere. In general, westerly zonal winds dominate the winter MLT, but the 2002-winter elucidates obvious differences when compared to other years, with many brief periods of easterly winds observed. The normalised Fourier power spectra in Figs. 5a and 6a depicts the presence of planetary waves (5-day, 10-day and 14- to 16-day waves) during the 2002 austral winter. In addition, Fig. $5 \mathrm{~b}$ and $6 \mathrm{~b}$ also showes presence of a 14- to 16-day wave in the meridional wind component during winter. The observation of the 14day oscillation is consistence with observations reported by Dowdy et al. (2004) and other authors.

The circulation in the stratosphere is characterized by a series of planetary wave events in 2002 winter that weakened 
the polar vortex and triggered the SSW in the late September. In Fig. 4, we compare the zonal winds at $\sim 94 \mathrm{~km}$ from SANAE HF radar with the zonal mean zonal winds from NCEP stratospheric data (at $10 \mathrm{hPa}$ ), and the results show that the reversal event in the MLT took place in a few days (about a week) prior to the reversal in the stratosphere. This behaviour indicates that there may be a downward propagation of circulation disturbance in the middle atmosphere. Similar results were also reported by Dowdy et al. (2004). SANAE HF radar results show similarities to the previous observations of the major SSWs both in the southern and the Northern Hemisphere. Lee et al. (2009) also reported the same behaviour of the middle atmosphere, where they studied the vertical structure and evolution of the wintertime Northern Hemisphere Annular Mode (NAM). In their study they concluded that the time evolution of NAM suggested that significant NAM anomalies typically appear first in the mesosphere and progress downwards.

Moreover, the response of the MLT region to the stratospheric warming depends on many different factors that still require more investigation. Mesospheric cooling is usually reported and associated with the major warming's in the Northern Hemisphere. On his explanation on the mesospheric cooling generally observed over Arctic SSWs, Holton (1983) suggested that eastwards gravity waves drag anomalies are consequence of a change in the filtering of parameterized gravity wave momentum fluxes when the stratospheric winds change from eastwards to westwards. However, Ren et al. (2008) observed mesospheric cooling over Antarctica 2002 major SSW and associated it with a net gravity wave drag induced upwelling rather than a suppression of dawnwelling. In the present work, we have used the SABER temperature data to examine a response of the thermal structure to the SSW in the stratosphere and MLT region. The stratosphere displays an unusual increase in temperature which started in the mid September, whiles MLT shows a cooling and temperature signature of inversion layers few days before the SSW occurrence. This behaviour of the MLT region is associated with energy deposition due to gravity wave breaking in the mesosphere. Gravity wave momentum deposition drives the pole-to-pole meridional wind circulation that in turn causes the departure of mesospheric temperature from radiative equilibrium, keeping the winter MLT warmer and summer MLT colder (Holton, 1983). Liu and Roble (2002) suggested that the penetration of gravity waves during the SSW can drive meridional circulation leading to adiabatic cooling and heating. The above reported behaviour of the middle atmosphere strengthens the idea of coupling between the stratosphere and the MLT region. Figure 7 also shows signature of minor warming in early September. A further study on characteristics of the planetary waves using SANAE HF radar during the SSW and investigation of Elliassen-Palm (EP) fluxes and potential vorticity (PV) gradients will be established in the ongoing study.
Regarding the observation errors of SABER in the upperMLT, Remsberg et al. (2008) validated the SABER version 1.07 kinetic temperature (which is also used in this study). Comparisons with other correlative data sets indicates that SABER temperature-versus-pressure $(T(p))$ was low by $2 \mathrm{~K}$ in the middle mesosphere. They also found a little difference between the local thermodynamic equilibrium (LTE) algorithm results below about $70 \mathrm{~km}$ from level 1.07 and 1.06, but there were substantial improvements for non-LTE results of level 1.07 for the upper-MLT region. The upper-MLT kinetic temperature from level 1.07 also found to be in good agreement with upper-MLT values from $\mathrm{OH}$ and $\mathrm{O}_{2}$ emissions and of the NA lidar return, at least within their mutual uncertainties. The above motioned findings from Remsberg et al. (2008) confidence in our results of level 1.07 SABER kinetic temperatures over SANAE base.

Acknowledgements. This work has been supported by National Research Foundation (NRF) of South Africa, South African Antarctica Program (SANAP) and French Embassy. The authors wish to acknowledge National Centre for Environmental Prediction (NCEP), Sounding of the Atmosphere using Broadband Emission Radiometry (SABER) on board the Thermosphere-IonosphereMesosphere-Energetics and Dynamics (TIMED) satellite and Data Access and Browsing System (DABS) for providing data.

Edited by: W. Ward

\section{References}

Andrews, D. G., Holton, J. R., and Leovy, C. B.: Middle Atmospheric Dynamics, Elsevier, New York, USA, 489 pp., 1987.

Baldwin, M. P. and Dunkerton, T. J.: Propagation of the Arctic Oscillation from the stratosphere to the troposphere, J. Geophys. Res., 104(D24), 30937-30946, 1999.

Baldwin, M., Hirooka, T., O’Neill, A., and Yoden, S.: Major stratospheric warming in the Southern Hemisphere in 2002: Dynamical aspect of the ozone hole split, SPARC Newsletter, 20, 24-26, 2003.

Bencherif, H., Charyulu, D. V., Amraoui, L. E., Peuch, V.-H., Semane, N., and Hauchecorne, A.: Examination of the 2002 major warming in the Southern Hemisphere using ground-based and Odin/SMR assimilated data: stratospheric ozone distribution and tropic/mid-latitude exchange, Can. J. Phys., 85, 1287-1300, 2007.

Bristow, W. A., Yee, J.-H., and Greenwald, A.: Simultaneous observations of July 1996 2-day wave event using the Super Dual Auroral Radar Network and the High Resolution Doppler Imager, J. Geophys. Res., 104, 12715-12721, 1999.

Cho, Y.-M. and Shepherd, G. G.: MLT cooling during stratospheric warming events, Geophys. Res. Lett., 31, L10104, doi:10.1029/2004GL019552, 2004.

Dowdy, A. J., Vincent, R. A., Murphy, D. J., Tsutsumi, M., Riggin, D. M., and Jarvis, M. J.: The large-scale dynamics of the Mesosphere-lower thermosphere during the Southern Hemisphere stratospheric warming of 2002, Geophys. Res. Lett., 31, L14102, doi:10.1029/2004GL020282, 2004. 
Espy, P. J. and Hibbins, R. E.: Mesospheric planetary waves over Antarctica during 2002, Geophys. Res. Lett., 32, L21804, doi:10.1029/2005GL023886, 2005.

Greenwald, R. A., Baker, K. B., Dudeney, J. R., Pinnock, M., Jones, T. B., Thomas, E. C., Villain, J. -P., Cerisier, J. -C., Senior, C., Hanuise, C., Hunsucker, R. D., Sofko, G., Koehler, J., Nielsen, E., Pellinen, R., Walker, A. D., Sato, N., and Yamagishi, H.: DARN/SuperDARN: A global view of the dynamics of high latitude convections, Space Sci. Rev, 71, 761-796, 1995.

Hall, G. E., MacDougall, J. W., Moorcroft, D. R., and St.-Maurice, J.-P.: Super Dual Auroral Radar Network observations of meteor echoes, J. Geophys. Res., 102, 14603-14614, 1997.

Hernandez, G.: Climatology of the upper mesosphere temperature above South Pole $\left(90^{\circ} \mathrm{S}\right)$ : Mesospheric cooling during 2002, Geophys. Res. Lett., 30(10), 1535, doi:10.1029/2003GL016887, 2003.

Hoffmann, P., Singer, W., and Keuer, D.: Variability of the mesospheric wind field at middle and Arctic latitude in winter and its relation to stratospheric circulation disturbances, J. Atmos. Sol. Terr. Phys., 64, 1229-1240, 2002.

Hoffmann, P.: Latitudina and longitudinal variability of mesospheric winds and temperatures during stratospheric warming events, J. Atmos. Sol. Terr. Phys., 69, 2355-2366, doi:10.1016/j.jastp.2007.06.010, 2007.

Holton, J. R.: A semi-spectral numerical model for wave-mean flow interactions in the stratosphere: Application to sudden stratospheric warmings, J. Atmos. Sci., 33, 1639-1649, 1976.

Holton, J. R.: The influence of gravity wave breaking on the general circulation of the middle atmosphere, J. Atmos. Sci, 40, 24972507, 1983.

Hussey, G. C., Meek, C. E., André, A. H., Manson, A. H., Sofko, G. J., and Hall, C. M.: A comparison of Northern Hemisphere wind using SuperDARN meteor trail and MF radar wind measurements, J. Geophys. Res., 105, 18053-18066, 2000.

Labitzke, K. and Naujokat, B.: The lower Arctic stratosphere in winter since 1952, SPARC Newsletter, 15, 11-14, 2000.

Lee, J., N, Wu, D. L., Manney, G. L., and Schwartz, M. J.: Aura Microwave Limb Sounder observations of the Northern Annular Mode: From the mesosphere to the upper troposphere. Geophys. Res. Lett., 36, L20807, doi:10.1029/2009GL040678, 2009.

Liu, H.-L. and Roble, R. G.: A study of self-generated stratospheric sudden warming and it mesosphere-lower thermosphere impacts using the coupled TIME-GCM/CCM3, J. Geophys. Res., 107(D23), 4695, doi:10.1029/2001JD001533, 2002.

Liu, H.-L. and Roble, R. G.: Dynamical coupling of the stratosphere and mesosphere in the 2002 Southern Hemisphere major stratospheric sudden warming, Geophys. Res. Lett, 32, L13804, doi:10.1029/2005GL022939, 2005.
Malinga, S. B. and Ruohoniemi, J. M.: The quasi-two-day wave studied using the Northern Hemisphere SuperDARN HF radars, Ann. Geophys., 25, 1767-1778, 2007, http://www.ann-geophys.net/25/1767/2007/.

Matsuno, T.: A dynamic model of the stratospheric sudden warming, J. Atmos. Sci., 28, 1479-1494, 1971.

Meriwether, J. W. and Gerrard, A. J.: Mesosphere inversion layers and stratosphere temperature enhancements, Rev. Geophys, 42, RG3003, doi:10.1029/2003RG000133, 2004.

Pancheva, D. V.: Quasi-2-day wave and tidal variability observed over Ascension Island during January/Ferbruary 2003, J. Atmos. Sol. Terr. Phys., 68, 390-403, 2006.

Plumb, R. A.: Stratospheric transport, J. Meteor. Soc. Japan, 80, 793-809, 2002.

Remsberg, E. E., Marshall, B. T., Garcia-Comas, M., Kreuger, D., Lingenfelser, G. S., Martin-Torres, J., Smith, A. K., Zhao, Y., Russell III, J. M., Mlynczak, M. G., Brown, C., Gordley, L. L., Thompson, R. E., Lopez-Puertas, M., She, C.-Y., and Taylor, M. J.: Assessment of quality of Version 1.07 temperature versus pressure profile in the middle atmosphere from TIMED/SABER, J. Geophys. Res., 113, D17101, doi:10.1029/2008JD010013, 2008.

Remsberg, E: On the verification of the quality of SABER temperature, geopotential height, and wind fields by comparison with Met Office assimilated analyses, J. Geophys. Res., 108(D20), 4628, doi:1029/2003JD003720, 2003.

Ren, S., Polavarapu, S. M., and Shepherd, T. G.: Vertical propagation of information in a middle atmosphere data assimilation system by gravity-wave drag feedbacks, Geophys. Res. Lett., 35, L06804, doi:10.1029/2007GL032699, 2008.

Sathishkumar, S. and Sridharan, S.: Planetary and gravity waves in the mesosphere and lower thermosphere region over Tirunelveli $\left(8.7^{\circ} \mathrm{N}, 77^{\circ} \mathrm{E}\right)$ during stratospheric warming events, Geophys. Res. Lett., 36, L07806, doi:10.1029/2008GL037081, 2009.

Shepherd, T. G.: The Middle atmosphere, J. Atmos. Sol. Terr. Phys., 62, 1587-1601, 2000.

Sivakumar, V., Morel, B., Bencherif, H., Baray, J. L., Baldy, S., Hauchecorne, A., and Rao, P. B.: Rayleigh lidar observation of a warm stratopause over a tropical site, Gadanki $\left(13.5^{\circ} \mathrm{N}\right.$; 79.2 ${ }^{\circ}$ E), Atmos. Chem. Phys., 4, 1989-1996, 2004, http://www.atmos-chem-phys.net/4/1989/2004/.

Torrence, C. and Compo, G. P.: A practical guide to wavelet analysis, B. Am. Meteor. Soc., 79, 61-78, 1998.

Walterschied, R. A., Sivjee, G. G., and Roble, R. G.: Mesospheric and lower thermosphere manifestations of a stratospheric warming over Eureka, Canada $\left(80^{\circ} \mathrm{N}\right)$, Geophys. Res. Lett., 27, 28972900, 2000. 